\title{
Can new paradigms bring new perspectives for mismatch negativity studies in schizophrenia?
}

\author{
Michał Jarkiewicz ${ }^{1 *}$ and Adam Wichniak ${ }^{1,2}$
}

\author{
* Correspondence: \\ mjarkiewicz@ipin.edu.pl \\ ${ }^{1}$ Third Department of Psychiatry, \\ Institute of Psychiatry and \\ Neurology, Sobieskiego 9, 02-957 \\ Warsaw, Poland \\ Full list of author information is \\ available at the end of the article
}

\begin{abstract}
Attenuation of mismatch negativity (MMN), event-related potential (ERP) that assess dysfunction in auditory change detection, is a robust finding in schizophrenia. Most studies on MMN in schizophrenia use a two-tone paradigm in which the deviant sound has a different duration or frequency. Because this oddball paradigm has provided consistent results over time and has proven to be a reliable research tool, it dominates this area of research. Over twenty years of investigation into MMN in schizophrenia have shown that change in any of the characteristics of stimulation results in MMN; however there is surprisingly little evidence on MMN in schizophrenia from studies using stimulation other than the typical oddball paradigm. In this paper we focus on studies which have assessed auditory change discrimination in schizophrenia employing paradigms other than a typical oddball. We also briefly discuss research on visual MMN in schizophrenia. The aim was to highlight how research using new paradigms has added to understanding of MMN in schizophrenia. In conclusion we discuss stimulation which could be useful for future research on MMN in schizophrenia.

Keywords: Mismatch negativity, Auditory, Visual, Event-related potential, Schizophrenia, Deviant sound, Oddball, Multi-feature, Roving paradigm
\end{abstract}

\section{Introduction}

The limited computational resources of human and animal neuronal circuitry are challenged every day by receiving large volumes of data from a diverse environment. According to the perceptual load theory (Lavie et al. 2014) automatic processes are used to assign neuronal computational resources to relevant stimuli and ignore irrelevant stimuli. One of the main roles of automatic pre-attentive processes in the brain is to identify relevant environmental stimuli and prevent exceeding the system's analytical capacity by the volume of data transferred from sensory receptors. There is mounting research evidence that the mismatch negativity (MMN) is the event-related potential (ERP) that reflects the detection of novelty. Neural networks recognize novel information by continually comparing incoming stimuli with recent perception (Näätänen et al. 2012). When incoming stimuli do not match the memory trace of previous stimuli the novelty is detected by mechanisms which result in generation of MMN.

The stimulation commonly used to elicit MMN is the auditory oddball paradigm; this consists of a series of standard tones infrequently interrupted by deviant tones 
which differ in some feature (usually duration or frequency) from the standard tones. The MMN waveform is calculated by subtracting the average standard stimuli evoked ERP from the average deviant evoked ERP waveform. The magnitude of MMN is thus dependent on formation of accurate memory traces in response to standard stimuli (Baldeweg and Hirsch 2014) and the ability to discriminate incoming deviant stimuli accurately. MMN-related information processing has been interpreted as detection of discrepancies between prediction model based on information about preceding and factual incoming stimuli (Winkler 2007). In a typical oddball paradigm the peak MMN amplitude occurs 100-250 ms after the presentation of the stimuli (Fig. 1). The largest negative MMN amplitude is recorded at fronto-central electrodes (Duncan et al. 2009).

Generation of MMN is context-dependent, which means that the design of the paradigm determines whether a given stimulus is perceived as standard or deviant. MMN can also be elicited by changing sequence pattern of stimulation rather than any physical feature of the stimuli, for example by repeating a stimulus in a sequence of changing stimuli (Macdonald and Campbell 2013). In summary, MMN reflects the brain's ability to detect auditory changes automatically.

Animal experiments have shown that elicitation of a MMN is directly dependent on the functionality of NMDA receptors. An experiment conducted on monkeys (Javitt et al. 1996) found that epidural MMNs were abolished by administration of an NMDA receptor antagonist. Research using the partial NMDA antagonist ketamine (Javitt et al. 2012) provided support for the hypothesis that glutamate plays an important role in the pathophysiology of auditory perception in psychosis.

Interestingly, as well as confirming the importance of the glutamatergic system to generation of MMN, human research has linked impaired detection of auditory deviants to vulnerability to ketamine-induced psychotic symptoms. A study of healthy volunteers (Umbricht et al. 2000) reported that after administration of ketamine total score on the Brief Psychiatric Rating Scale (BPRS) and psychosis factor scores were

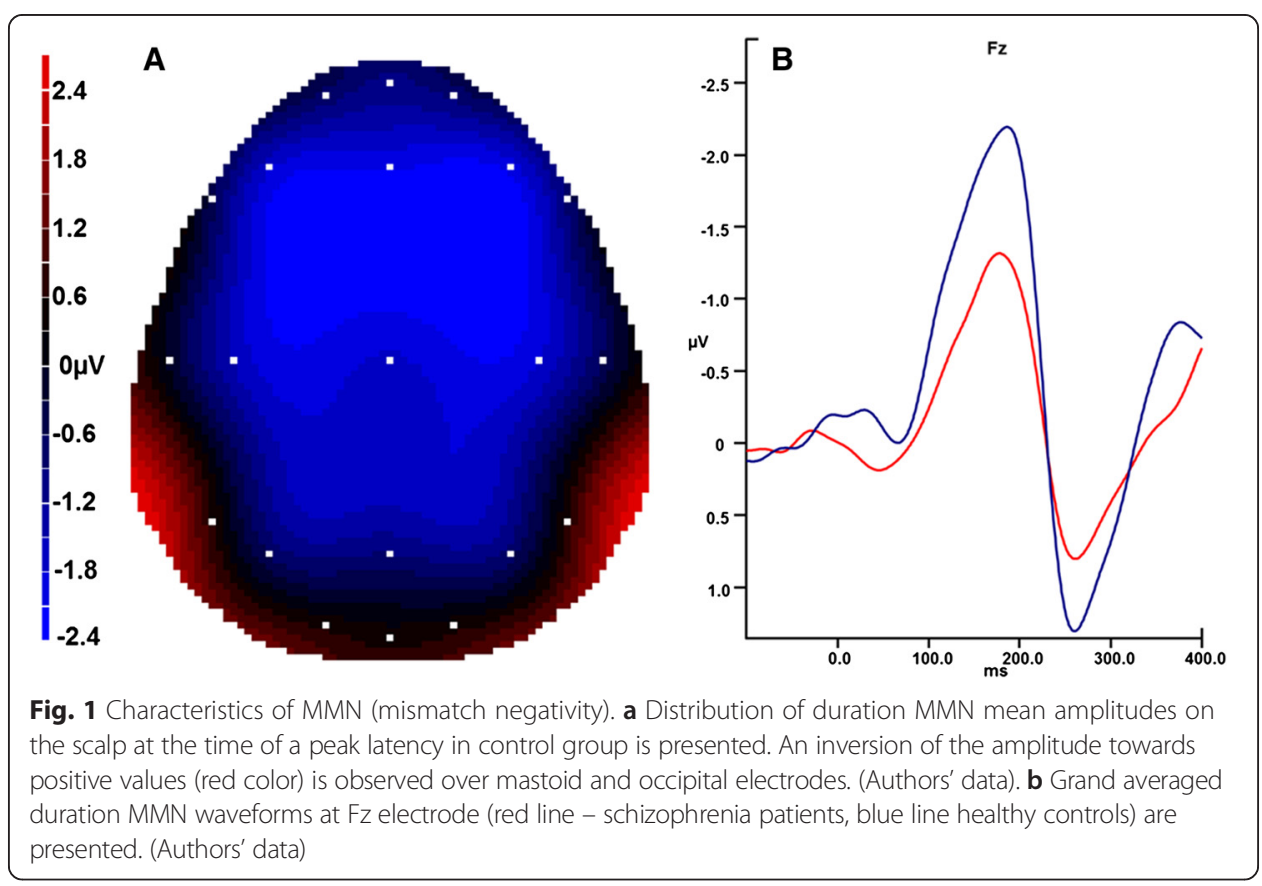


significantly higher, and MMN amplitude was significantly smaller, than after administration of a placebo. Importantly, subsequent analysis of the data from this experiment (Umbricht et al. 2002) revealed a negative correlation between MMN amplitude during the placebo and total BPRS score in the ketamine condition).

The auditory components of MMN generators are located in frontal and bilaterally in temporal lobes in primary and secondary auditory cortices (Alho 1995). Importantly for this discussion, the exact location of generators varies according to the nature of the stimulation used (Alho 1995; Tiitinen et al. 1993).

Since it was first described (Näätänen et al. 1978) the MMN has been applied in numerous areas of research (Näätänen et al. 2012). MMN is elicited automatically; the process does not depend on the attention of the subject, so that it has been used frequently in research with less cooperative subjects. Impairment of MMN in neuropsychiatric clinical populations has been associated with cognitive deficits (Näätänen et al. 2011; Näätänen et al. 2014). In this paper we review research on MMN in schizophrenia, focusing on research using stimulation other than the auditory oddball paradigm.

\section{Review}

\section{"State of the art" - MMN in schizophrenia}

Attenuation of the MMN elicited by changes in auditory stimulation is a consistent finding in patients diagnosed with schizophrenia (Umbricht and Krljes 2005). Interest in MMN in schizophrenia started with the first study to show reduced MMN amplitude in schizophrenia patients relative to healthy controls using an oddball paradigm with duration deviants (Shelley et al. 1991). This finding has been replicated numerous times and linked to clinical findings, for example for duration deviants in oddball reduced MMN was associated with poor functioning measured by Global Assessment of Functioning Scale (Light and Braff 2005a, 2005b) and deficits in social cognition in schizophrenia (Wynn et al. 2010).

The largest study of MMN in schizophrenia conducted to date (428 schizophrenia patients and 286 non-psychiatric comparison subjects; Rissling et al. 2012) confirmed that schizophrenia patients showed a reduction in MMN amplitude to duration but did not find correlations between diminished MMN and clinical characteristics such as the number of hospitalizations, duration of illness or intensity or frequency of positive or negative symptoms.

MMN is also a promising biomarker for conversion to psychosis in high-risk patients (Bodatsch et al. 2011; Perez et al. 2014; Higuchi et al. 2014; for review see Nagai et al. 2013b; Näätänen et al. 2015). Although dysfunction in auditory deviance prediction has been reported in number of clinical populations (Näätänen et al. 2012), there is also some evidence that MMN reduction is specific to schizophrenia (Baldeweg and Hirsch 2014; Umbricht et al. 2003). A large cohort study of schizophrenia and control subjects (Light et al. 2012) compared the endophenotypic status of MMN with other neurophysiological and neuropsychological indicators. MMN parameters were stable over a one-year period and, along with P3a (part of the P300 event-related potential), was the best candidate for an endophenotype of schizophrenia. A recent review (Light and Nääänen 2013) described MMN as a "breakthrough biomarker" for NMDA receptor dysfunction in schizophrenia.

Further, Rasser et al. (2011) linked MMN deficits to the anatomical and functional brain changes associated with schizophrenia, by showing that loss of cortical tissue in 
schizophrenia patients was correlated with a reduction in the MMN to frequency deviance, and that reductions in gray matter volume in the right Heschl's gyrus were correlated with reduction in the MMN to duration.

There has been a lot of research on associations between MMN and demographic variables. It was shown that frequency MMN was smaller in chronic but not first episode schizophrenia patients (Salisbury et al. 2002). A later study (Kiang et al. 2009) of large groups of participants found a significant reduction in duration MMN amplitude with age in both healthy controls and schizophrenia patients aged between 18 and 65 years old. A study which compared frequency and duration deviance MMN found that duration MMN was more stable over the course of schizophrenia (Michie et al. 2000); there is however evidence that the reduction in duration MMN is greater in the early stages of schizophrenia or even in patients in the prodromal stage (Bodatsch et al. 2011; Perez et al. 2014; Higuchi et al. 2014; Hermens et al. 2010; Jahshan et al. 2012; Nagai et al. 2013a); similar findings have been reported for the magnetic counterpart of MMN (Shin et al. 2012).

In summary, MMN has played a significant role in research on schizophrenia, but it is worth asking if it remains a valuable and informative technique for research in this field.

The potential of MMN as a technique for research on cognitive deficits was noted by CNTRICS (Cognitive Neuroscience Treatment Research to Improve Cognition in Schizophrenia) which described $\mathrm{MMN}$ as a reliable, 'mature' investigation tool (Green et al. 2009; Luck et al. 2011) and recommended it as a method of evaluating cognition in clinical trials.

A recent review (Todd et al. 2013) recommended the intensive use of MMN in translational studies as means of investigating the pathophysiology of schizophrenia. Nevertheless, it has also been argued that future research on MMN in schizophrenia would benefit from the use of more sophisticated paradigms than the typical oddball paradigm (Umbricht and Krljes 2005).

\section{Beyond duration and frequency deviants}

Our brief overview of the use of MMN in research on schizophrenia suggested that differences in the deficits associated with frequency or duration deviance change detection are important. It has been concluded (Umbricht and Krljes 2005; Näätänen and Kähkönen 2009) that schizophrenia is associated with greater impairment in detection of changes in duration than changes in frequency of stimulation and that this difference is especially noticeable early in the course of illness. Moreover, duration of illness seems to have greater impact on frequency MMN (the amplitude of frequency MMN decreases with time after diagnosis) than on duration MMN, which appears to be more stable over the course of schizophrenia. It should be noted, however, that a recent metaanalysis suggested that duration MMN was also affected by normal aging in non-psychiatric populations (Cheng et al. 2013b). It has also been argued that all MMN paradigms rely on a similar neuronal mechanism and that use of different stimulation modes and formats might be an obstacle to comparative analysis (Todd et al. 2013).

There are only a few studies on schizophrenia patients whereby methodology diverge from the traditional oddball with frequency or duration deviants. The summary in Table 1 suggests that using novel deviants in the oddball task or a more complex stimulation design can provide interesting, new information. 
Table 1 MMN studies of schizophrenia with stimulation beyond duration and frequency deviants

\begin{tabular}{|c|c|c|c|c|c|}
\hline$\underline{\text { Study }}$ & Subjects & Paradigm & Deviants & Main findings & Comments and conclusions \\
\hline Baldeweg et al. 2002 & $\begin{array}{l}14 \text { schizophrenia patients } \\
\text { and } 14 \text { healthy controls }\end{array}$ & $\begin{array}{l}\text { Roving paradigm (changing } \\
\text { number of standards between } \\
\text { deviants: } 2,6,18 \text { or } 38 \text { ) }\end{array}$ & $\begin{array}{l}\text { Frequency }(12 \text { frequencies from } \\
700 \text { to } 1250 \mathrm{~Hz}) \text { and duration } \\
\text { deviants }(50 \mathrm{~ms})\end{array}$ & $\begin{array}{l}\text { Attenuation of MMN amplitude over } \\
\text { frontal sites but not over mastoids } \\
\text { was found in schizophrenia. }\end{array}$ & $\begin{array}{l}\text { Isolated frontal MMN generator } \\
\text { impairment in schizophrenia } \\
\text { was suggested. }\end{array}$ \\
\hline Baldeweg et al. 2004 & $\begin{array}{l}28 \text { schizophrenia patients; } \\
20 \text { healthy controls }\end{array}$ & $\begin{array}{l}\text { Roving paradigm (changing } \\
\text { number of standards between } \\
\text { deviants: } 2,4,8,18 \text { or } 36 \text { ) }\end{array}$ & $\begin{array}{l}\text { Frequency (12 different frequencies } \\
\text { ranging from } 700 \text { to } 1250 \mathrm{~Hz} \text { ) and } \\
\text { duration deviants }(50 \mathrm{~ms})\end{array}$ & $\begin{array}{l}\text { "MMN slope" (mean value of a } \\
\text { relative gain of MMN amplitudes } \\
\text { observed each time the number } \\
\text { of standards was increased) was } \\
\text { negatively correlated with } \\
\text { cognitive tests ratings. }\end{array}$ & $\begin{array}{l}\text { The dysfunction in memory trace } \\
\text { formation seem to contribute to } \\
\text { attenuation of MMN. For the first } \\
\text { time reduction of MMN was } \\
\text { associated with worse cognitive } \\
\text { performance in schizophrenia. }\end{array}$ \\
\hline Baldeweg and Hirsch 2014 & $\begin{array}{l}49 \text { schizophrenia, } \\
25 \text { bipolar, } \\
15 \text { dementia patients; } \\
49 \text { healthy controls }\end{array}$ & $\begin{array}{l}\text { Roving paradigm (changing } \\
\text { number of standards between } \\
\text { deviants: } 2,6 \text { or } 36 \text { ) }\end{array}$ & $\begin{array}{l}\text { Frequency (12 different frequencies } \\
\text { ranging from } 700 \text { to } 1250 \mathrm{~Hz} \text { ) and } \\
\text { duration deviants }(75 \mathrm{~ms})\end{array}$ & $\begin{array}{l}\text { Only for schizophrenia patients a } \\
\text { significant attenuation of MMN, } \\
\text { when compared to healthy } \\
\text { controls was found. }\end{array}$ & $\begin{array}{l}\text { This study provided evidence for } \\
\text { specificity of reduction of MMN } \\
\text { in schizophrenia. }\end{array}$ \\
\hline Fisher et al. 2008b & $\begin{array}{l}24 \text { schizophrenia patients } \\
\text { and } 12 \text { healthy controls }\end{array}$ & $\begin{array}{l}3 \text { different oddballs } \\
\text { (stimulation replicated from } \\
\text { Kasai et al. (2002)) }\end{array}$ & $\begin{array}{l}\text { Tone duration deviant, phenome } \\
\text { duration deviant, across-phoneme } \\
\text { deviant }\end{array}$ & $\begin{array}{l}\text { Perceived clarity of AVH (auditory } \\
\text { verbal hallucinations) correlated } \\
\text { with reduction of MMN elicited } \\
\text { by phenome paradigms but not } \\
\text { pure tone stimulation. }\end{array}$ & $\begin{array}{l}\text { This study opposes general } \\
\text { notion that MMN is not } \\
\text { influenced by symptoms } \\
\text { experienced by patients. }\end{array}$ \\
\hline Fisher et al. 2008a & $\begin{array}{l}24 \text { schizophrenia patients } \\
\text { and } 12 \text { healthy controls }\end{array}$ & $\begin{array}{l}\text { Multi-feature paradigm } \\
\text { developed by Näätänen } \\
\text { et al. (2004) }\end{array}$ & $\begin{array}{l}\text { Duration, frequency, location, gap } \\
\text { and intensity deviants }\end{array}$ & $\begin{array}{l}\text { In the hallucinating patients group } \\
\text { duration, frequency and intensity } \\
\text { MMN amplitude was significantly } \\
\text { reduced, when compared to } \\
\text { healthy controls and } \\
\text { non-hallucinating patients. }\end{array}$ & $\begin{array}{l}\text { It is another study from the } \\
\text { same research group providing } \\
\text { evidence that forming MMN } \\
\text { might be influenced by the } \\
\text { individuals clinical status. }\end{array}$ \\
\hline Fisher et al. 2012b & $\begin{array}{l}12 \text { schizophrenia patients } \\
\text { and } 15 \text { healthy controls }\end{array}$ & $\begin{array}{l}\text { Multi-feature paradigm } \\
\text { developed by Näätänen } \\
\text { et al. (2004) }\end{array}$ & $\begin{array}{l}\text { Duration, frequency, location, gap } \\
\text { and intensity deviants }\end{array}$ & $\begin{array}{l}\text { Correlations of AVH features } \\
\text { measured with PSYRATS } \\
\text { (Psychotic Symptom Rating } \\
\text { Scale) scale with attenuated } \\
\text { gap and location MMN and } \\
\text { negative correlation of } \\
\text { chlorpromazine equivalents } \\
\text { and location MMN amplitude. }\end{array}$ & $\begin{array}{l}\text { Applying deviants other than } \\
\text { frequency and duration was } \\
\text { informative for analysing } \\
\text { auditory stimuli processing } \\
\text { in schizophrenia. }\end{array}$ \\
\hline
\end{tabular}


Table 1 MMN studies of schizophrenia with stimulation beyond duration and frequency deviants (Continued)

\begin{tabular}{|c|c|c|c|c|c|}
\hline Fisher et al. 2012a & 12 schizophrenia patients & $\begin{array}{l}\text { Optimized multi-feature } \\
\text { paradigm developed by } \\
\text { Fisher et al. (2011b }\end{array}$ & $\begin{array}{l}\text { Duration, frequency and intensity } \\
\text { deviants }\end{array}$ & $\begin{array}{l}\text { An administration of a nicotine } \\
\text { significantly shortened latency } \\
\text { of intensity MMN. Changes in } \\
\text { intensity MMN were correlated } \\
\text { with increased AVH clarity. }\end{array}$ & $\begin{array}{l}\text { Stimulating nicotine action } \\
\text { seems to have more significant } \\
\text { impact on intensity than on } \\
\text { duration or frequency MMN. }\end{array}$ \\
\hline Fisher et al. 2011a & $\begin{array}{l}12 \text { schizophrenia patients } \\
\text { and } 12 \text { healthy controls }\end{array}$ & $\begin{array}{l}\text { Optimized multi-feature } \\
\text { paradigm developed by } \\
\text { Fisher et al. (2011b) }\end{array}$ & $\begin{array}{l}\text { Duration, frequency and intensity } \\
\text { deviants }\end{array}$ & $\begin{array}{l}\text { Reduction of duration and } \\
\text { intensity MMN amplitude } \\
\text { correlated with positive } \\
\text { symptom ratings. Attenuation } \\
\text { of duration MMN was more } \\
\text { significant in patients with } \\
\text { more severe AVH. }\end{array}$ & $\begin{array}{l}\text { This study extends research on } \\
\text { neurophysiological background } \\
\text { of positive symptoms in } \\
\text { schizophrenia. }\end{array}$ \\
\hline Fisher et al. 2014 & $\begin{array}{l}10 \text { schizophrenia patients } \\
\text { and } 13 \text { healthy controls }\end{array}$ & Oddball & $\begin{array}{l}\text { Pure tone frequency deviant and } \\
\text { environmental sound deviant } \\
\text { (baby cry) }\end{array}$ & $\begin{array}{l}\text { Amplitude and latency of MMN } \\
\text { to novel environmental deviant } \\
\text { was significantly reduced in } \\
\text { schizophrenia. Amplitude of } \\
\text { MMN was positively correlated } \\
\text { with positive symptoms and } \\
\text { AVH ratings. }\end{array}$ & $\begin{array}{l}\text { This study explores applicability } \\
\text { of a novel stimulation in } \\
\text { eliciting ERP's in schizophrenia. }\end{array}$ \\
\hline Friedman et al. 2012 & $\begin{array}{l}26 \text { schizophrenia patients } \\
\text { and } 19 \text { healthy controls }\end{array}$ & $\begin{array}{l}\text { Modified oddball; all stimuli } \\
\text { were harmonics }(500 \mathrm{~Hz}, \\
1000 \mathrm{~Hz} \text { and } 1500 \mathrm{~Hz} \text { for } \\
\text { standards) }\end{array}$ & $\begin{array}{l}\text { Intensity, frequency and duration } \\
\text { deviants }\end{array}$ & $\begin{array}{l}\text { Poorer premorbid educational } \\
\text { status, longer illness duration } \\
\text { and worse scoring on the } \\
\text { independent living scale } \\
\text { correlated with reduced } \\
\text { duration and intensity MMN. }\end{array}$ & $\begin{array}{l}\text { Results of the study confirm } \\
\text { importance for evaluation of } \\
\text { different deviant features in MMN } \\
\text { research in schizophrenia. }\end{array}$ \\
\hline Gjini et al. 2010 & $\begin{array}{l}12 \text { schizophrenia patients } \\
\text { and } 12 \text { healthy controls }\end{array}$ & $\begin{array}{l}\text { Oddball with three deviants } \\
\text { and oddball with single } \\
\text { abstract deviant }\end{array}$ & $\begin{array}{l}\text { Frequency, duration, white-noise } \\
\text { and abstract feature deviants } \\
\text { (standards were paired tones of } \\
\text { ascending frequency and deviants } \\
\text { paired tones of descending } \\
\text { frequency) }\end{array}$ & $\begin{array}{l}\text { Negative correlation between } \\
\text { P50 gating and abstract MMN } \\
\text { amplitude was weaker in } \\
\text { schizophrenia patients than in } \\
\text { healthy controls. Only white-noise } \\
\text { MMN was significantly reduced } \\
\text { in the schizophrenia group. }\end{array}$ & $\begin{array}{l}\text { Introducing novel deviants } \\
\text { enabled more insight into auditory } \\
\text { information processing in } \\
\text { schizophrenia. No significant } \\
\text { results were found for frequency } \\
\text { and duration MMN. }\end{array}$ \\
\hline
\end{tabular}


Table 1 MMN studies of schizophrenia with stimulation beyond duration and frequency deviants (Continued)

(Kawakubo et al 2007) 13 schizophrenia patients 3 different oddballs $\quad$ Tone duration deviant, phenome (stimulation replicated from duration deviant, across-phoneme Kasai et al. (2002)) deviant

Kreitschmann-Andermahr 15 schizophrenia patients Oddball et al. 1999 and 16 healthy controls

Matthews et al. 2007

18 schizophrenia patients 3 oddballs (each with and 19 healthy controls different deviant type)

Rissling et al. 2013

20 schizophrenia patients Oddball and 20 healthy controls

Thönnessen et al. 2008

12 schizophrenia patients Pure-tone oddball and and 12 healthy controls multi-feature paradigm designed by Näätänen et al. (2004)
Two different frequency deviants $(1050 \mathrm{~Hz}$ and $5000 \mathrm{~Hz}$ ) and tone omission deviant

A reduction of MMNm (MMN

magnetic counterpart) for all

deviants show dysfunction of

temporal MMN generators.

Three types of deviants with delayed arrival-time or different phase or loudness of a stimuli

for the left and right ear

Duration and white-noise deviant

zophrenia group showed

dysfunction in processing spatia

(arrival-time or phase difference) but not loudness deviants when compared to healthy controls.

Attentional demand (both auditory and visual) modulated white-noise MMN and P3a in schizophrenia patients and healthy controls. Attentional modulation of auditory change detection seem to be intact in schizophrenia.

Duration and intensity deviants in The MMNm was significantly the oddball; duration, frequency, reduced in the schizophrenia intensity, gap and location group over left auditory cortex deviants in the multi-feature paradigm; for all deviants (only gap and location over right auditory cortex
Significant correlation was found between larger MMN to across-phoneme deviant and better improvement in social scores after 3 month social skills training.

Phoneme oddball was better than tone oddball in predicting improvement in social skills.

The reduction of an omission MMNm suggests that an error prediction impairment contributes to schizophrenia deficits.

The results suggest specific impairment in exact discrimination of time cues in schizophrenia.

MMN to white-noise deviant seems to be more sensitive to changes in attention load and direction (visual vs auditory) than duration MMN.

This study suggest that MMNm elicited by multi-feature is more accurate than oddball paradigm in identifying deficits in forming presented in multi-feature paradigm. No significant difference between groups were found for oddball. 
Table 1 MMN studies of schizophrenia with stimulation beyond duration and frequency deviants (Continued)

\begin{tabular}{|c|c|c|c|c|c|}
\hline Todd et al. 2008 & $\begin{array}{l}43 \text { schizophrenia patients } \\
\text { and } 42 \text { healthy controls }\end{array}$ & Oddball & Intensity, frequency and duration & $\begin{array}{l}\text { A reduction in duration and } \\
\text { intensity MMN in short-illness } \\
\text { patients with schizophrenia. In a } \\
\text { long-illness group only frequency } \\
\text { MMN were significantly reduced. }\end{array}$ & $\begin{array}{l}\text { This study revealed potential for } \\
\text { more variable stimulation to } \\
\text { create patterns for some groups } \\
\text { of patients and healthy controls. }\end{array}$ \\
\hline Todd et al. 2014 & $\begin{array}{l}33 \text { schizophrenia patients } \\
\text { and } 58 \text { healthy controls }\end{array}$ & $\begin{array}{l}\text { Oddball composed of two } \\
\text { stimuli sequences one with } \\
\text { a pseudorandom and one } \\
\text { with fixed order of stimuli }\end{array}$ & $\begin{array}{l}\text { Duration, frequency, intensity } \\
\text { and ascending frequency } \\
\text { deviant; in fixed order } \\
\text { sequence all frequency deviants } \\
\text { were preceded with duration } \\
\text { and all ascending frequency } \\
\text { preceded intensity ones. }\end{array}$ & $\begin{array}{l}\text { Intensity, duration and ascending } \\
\text { frequency but not frequency MMN } \\
\text { were smaller in schizophrenia. } \\
\text { When the deviants were paired } \\
\text { MMN for the second deviant was } \\
\text { equally reduced in schizophrenia } \\
\text { patients and healthy controls. }\end{array}$ & $\begin{array}{l}\text { Method used for a computation } \\
\text { of MMN (traditional vs } \\
\text { feature-controlled) significantly } \\
\text { influenced results. Introduced } \\
\text { oddball design failed to reveal } \\
\text { additional impairment in stimuli } \\
\text { processing in schizophrenia. }\end{array}$ \\
\hline
\end{tabular}


Although there is a substantial and increasing body of evidence that auditory change detection is impaired in schizophrenia, issues such as the influence of antipsychotic medication and symptom severity on MMN generation require further investigation. Use of novel stimulation formats such as multi-feature paradigms (Fisher et al. 2008b, Fisher et al. 2011a, Fisher et al. 2012a, Fisher et al. 2012b) or novel stimuli like phonemes (Fisher et al. 2008a) or real-life sounds such as babies' cries (Fisher et al. 2014) has provided evidence on associations between size of MMN and the clarity or subjective location (outside or inside the head) of auditory hallucination. Studies which used typical oddball tasks were inconclusive with respect to the association between auditory hallucinations in schizophrenia and MMN amplitude (Fisher et al. 2012b).

A study using Japanese phonemes as the deviant stimuli in an oddball reported that schizophrenia patients showed an increase in MMN amplitudes after 3 months of social skills training (Kawakubo et al. 2007). The key point from the perspective of this review is that this study also used a traditional oddball paradigm and that there was no change in the amplitude of MMN to duration deviants after training. It is important to emphasize, however, that this study did not include a control group and the sample was very small $(n=13)$.

The MMN waveform has several components (Todd et al. 2013), which are difficult to disentangle applying a two-tone oddball paradigm. Research using a roving paradigm in which the standard stimuli were varied provided more insight into dysfunction of MMN mechanism in schizophrenia as it provided evidence for deficits in the formation of memory traces for standards (Baldeweg et al. 2004; Baldeweg and Hirsch 2014). Another oddball study (Matthews et al. 2007) showed that novel deviants could be used to investigate the exact nature of the deficit in discrimination of time cues in schizophrenia.

There are also technical advantages to using a multi-feature paradigm rather than typical oddballs, namely: more information about detection of various stimuli can be collected in shorter recording time (Näätänen et al. 2004) and signal to noise ratio is better (Thönnessen et al. 2008).

\section{Visual MMN in schizophrenia}

Although human perception relies more on the visual than the auditory system, it is only recently that research on MMN in schizophrenia has been extended to include tasks involving visual stimuli. The report of deficits in detecting changes in visual stimuli in schizophrenia was published after 17 years of intensive research on auditory change detection in schizophrenia (Urban et al. 2008). In this study the greatest reduction in the amplitude of the visual MMN (vMMN) in schizophrenia was recorded at the frontal midline electrode (there was also a reduction in amplitude at the parietal and occipital electrodes). Interest in vMMN is rising, but the findings of this pioneering study on vMMN in schizophrenia have been replicated in just a few studies.

Attenuation of visual MMN in schizophrenia was subsequently confirmed at posterior scalp regions (Neuhaus et al. 2013). These results should be analyzed carefully as they were obtained using a task which did not divert attention from deviant stimuli, which has been suggested to be an essential condition for observation of a vMMN (Stefanics et al. 2014). The authors of the study argued, however, that they could separate neighboring, probably attention-dependent negativities from vMMN (Neuhaus et al. 2013). 
A third study used affective stimuli - fearful or happy faces - to generate vMMN (Csukly et al. 2013). In the schizophrenia group there was no significant vMMN response to deviant stimuli. Group comparisons revealed that the larger vMMN elicited by fearful faces in the control group was localized at the central and temporal electrodes, whereas the vMMN to happy faces was localized to central electrodes. In this study the schizophrenia group also showed worse facial recognition performance. This study was also the first to demonstrate an association between impairments in a putative error prediction mechanism and impairments in recognition of facial expressions.

Previous studies have reported an association between worse global and social functioning in schizophrenia and the amplitude of the MMN to tone increment (Light and Braff 2005a) and emotion recognition (Hooker and Park 2002). It was suggested (Csukly et al. 2013) that reduced vMMNs in schizophrenia patients were a reflection of impairments in emotion recognition, which is undoubtedly one of the crucial, nonverbal determinants of social functioning, and that vMMN might be an indicator of processes linking basic neurophysiological findings to clinical findings in schizophrenia.

Research implementing vMMN paradigms in schizophrenia is evolving. At present, these studies pose more questions about schizophrenia than they have answered. Visual stimulation requires more patient cooperation than auditory stimulation; it is important that subjects comply with instructions not to look away from the monitor. Nevertheless, the studies discussed in this section provide evidence that the deficit in MMN in schizophrenia is not confined to the auditory modality. Further research is needed if visual $\mathrm{MMN}$ is to become as important to schizophrenia research as based on MMN derived from processing of auditory stimuli.

\section{Suggestions for future research}

The large and increasing number of publications on $\mathrm{MMN}$ in various research fields means that there is also a considerable amount of work on refining paradigms and study designs. Clinical research on conditions such as schizophrenia and autism could benefit from this methodological research.

Although making detailed recommendations for research on specific disorders is beyond the scope of our review we suggest that it is important to pay attention to the stimuli used to elicit MMNs as impairments in MMN may be dependent on different stimuli in different clinical conditions and may well be different from the impairment found in schizophrenia (Näätänen et al. 2012). This means that it is important to tailor the task to the population being investigated. Näätänen et al. (2014) concluded, with respect to assessment of the mechanisms underlying MMN impairments associated with disorders of language "the use of more complex stimulation may reveal information not otherwise obtained".

In our opinion the studies reviewed above indicate that different paradigms are sensitive to different underlying impairments; we suggest that diversifying the tasks used to elicit MMN in schizophrenia research would pay dividends. This perspective is based on information processing theories and basic research on perception and analysis of incoming stimuli.

First of all, we use perception load theory to support our position. Perception load theory posits that even a simple stimulus can impose a high load on the perceptual system if features such as size or lack of contrast mean that it is at the limits of the 
sensory system (Lavie et al. 2004). A typical oddball task using a duration deviant does not exceed the sensory discriminatory capacity of schizophrenia patients: the longer auditory stimuli are detected and this is reflected in the presence of a MMN, albeit one which is smaller than that observed in healthy controls. Only when the discrimination becomes more difficult, as in the roving paradigm, can one observe phenomenona associated with high perceptual load. When a roving paradigm was used deviants which were presented after a small number of standards elicited MMN in healthy controls but not in schizophrenia patients (Baldeweg et al. 2004) and similar results were reported with visual stimuli (Csukly et al. 2013). There is, however, some research which conflicts with the hypothesis that reductions in MMN amplitude are a result of discrimination deficits. It was shown that the difference between MMN amplitudes in schizophrenia patients and controls was greater when there was a bigger difference between the frequency of standard and deviant stimuli (Javitt et al. 1998). Use of a wider range of MMN paradigms would help to create neurophysiological profiles for particular perceptual impairments and clinical conditions. It would then be possible to investigate associations between neurophysiological characteristics and neuropsychological or social variables. There has already been a study of the relationship between clozapine dose and MMN amplitude using frequency and duration deviance (Horton et al. 2011).

Second, the evidence suggests that analysis of more complex aspects of auditory stimuli, such as harmonic properties, involves more cortical region. Moreover, it has been suggested that organization of all brain regions forming auditory system is based on a harmonic principle (Wang 2013). Obviously, research which relies on discrimination between two sinusoidal tones cannot provide insight into the physiology of such a complex functional system.

Additionally, the sinusoidal tones used in typical oddball tasks are very different from the kinds of auditory stimuli we encounter in everyday life, including verbal communication, as these are harmonic.

A study using magnetoencephalography reported that the organization of MMN generators was tonotopic (Tiitinen et al. 1993). It was reported that a duration deviant created from harmonics results in a larger MMN than a single tone sinusoidal deviant (Zion-Golumbic et al. 2007). It was argued that every feature of a sound is analyzed separately and that changes are additive; duration of harmonic deviant stimuli elicit large MMN because they represent alterations in the length of all features of a sound. It was on this basis that multi-feature paradigms where designed. The paradigm using stimuli consisting of eight partials (Pakarinen et al. 2010) is of particular interest. Authors (Pakarinen et al. 2010) introduced novel deviants by manipulating the intensity or frequency of one component of a stimulus. They proposed a paradigm in which there was no 'standard' stimulus, based on the assumption that each feature of a stimulus is analyzed separately. In a sequence of complex stimuli only one sound feature changes from one stimulus to the next, while others features are repeated and act as standards.

An issue which is critical to the hypotheses about the mechanism underlying the MMN is whether it is triggered by violation of predictions about the incoming stimuli (Winkler 2007). It has also been suggested that MMN arise because there is adaptation in a group of neurons responding to standards and that subsequent presentation of a deviant stimulus elicits a different group of un-adapted neurons thus generating a negative ERP 
waveform (Garrido et al. 2009). A recent study of healthy volunteers provided strong evidence for the hypothesis that MMNs are derived from violation of predictions (Wacongne et al. 2011). A paradigm which provided violations of local and global (across several sequences of sounds) expectations was used to test the validity of the two hypotheses. It is notable that a previous study using a very similar design found important differences in how auditory stimuli were processed by healthy controls and patients with disorders of consciousness (Bekinschtein et al. 2009). Interestingly, studies using a roving paradigm have provided evidence that both adaptation and predictive mechanisms contribute to MMN (Schmidt et al. 2012, Schmidt et al. 2013). An important issue for schizophrenia research is whether impairments in prediction or adaptation mechanisms or both are responsible for deficits in detection of changes in auditory stimulation. A model based on data from roving paradigm studies suggests that deficits in MMN are the result of impairments in neuronal circuits responsible for predictions about stimuli (Baldeweg and Hirsch 2014).

Schizophrenia research will only benefit from introducing novel stimulation paradigms if there is general agreement on the method of eliciting, recording and quantifying MMN (Duncan et al. 2009). Campanella and Colin (2014) pointed out that when studies do not use recommended methods it is more difficult to interpret the results. Applying new paradigms requires additional effort to develop new methodological recommendations for them and this could explain that new stimulation is not widely used in basic, and especially clinical research.

The issue of the specificity of MMN deficits to schizophrenia also arises when considering vMMN as there is evidence of dysfunction in visual processing in bipolar disorder (Maekawa et al. 2013) and major depressive disorder (Chang et al. 2011). The effects of other variables such as aging, duration of illness, psychopathology, antipsychotics etc. on vMMN are not known. But even at this stage it is clear that vMMN has potential as a tool for investigating recognition of affective stimuli. A paradigm using schematic faces to depict emotions is a notable recent introduction (Kreegipuu et al. 2013); this followed previous reports on vMMN elicited in emotion recognition paradigm (Susac et al. 2004). A task using changing auditory affective stimuli has also been shown to elicit MMN and has been used in research on autism (Fan and Cheng 2014). Another study has linked affective prosody (visual stimulation) and deficits in auditory discrimination (Jahshan et al. 2013). There is also a growing body of evidence that deficits in visual perception in schizophrenia (Butler et al. 2007; Brenner et al. 2009) are due to an impairment in the mechanisms used to convey visual information to the visual cortex.

The studies we have discussed can be used as a basis for further investigation into relationships between bottom-up and top-down visual processing in schizophrenia. The features of the vMMN, particularly its cortical location and the fact that it does not depend on attention, make it a potentially interesting tool for research on sensory integration processes in schizophrenia.

\section{Conclusions}

In spite of the fact that MMN can be elicited by a great variety of stimuli it seems that most data on MMN in schizophrenia is based on research using an auditory oddball paradigm with deviants to duration and frequency. The advantages of this are that it makes it easy to compare studies; however the homogeneity of stimuli may limit the 
development of MMN as a valuable biomarker. For example there is evidence of agerelated changes in the amplitude of frequency (Cheng et al. 2013a) and duration (Cheng et al. 2013b) MMN; such effects might bias the results of controlled studies of MMN in schizophrenia (Todd et al. 2014).

Research based on use of the other than typical two-tone oddball paradigm has quite often provided new information on auditory impairments in schizophrenia, contributing in particular to understanding of the pathophysiology of MMN deficits and their relationship to use of antipsychotic medication or particular symptoms. Research on detection of changes in visual stimulation has recently emerged as an interesting alternative to research on traditional auditory MMN. Although data on vMMN in schizophrenia are scarce, visual stimuli may be more useful for investigating MMN related to, for example, emotion recognition.

The body of evidence presented in this review supports the notion that use of a wider range of stimulation other stimulation modalities has enabled researchers to broaden investigations into the MMN system and thereby improve our understanding of deficits in pre-attentive change detection in this clinical population.

\section{Competing interests}

The authors declare that the research was conducted in the absence of any commercial or financial relationships that could be construed as a potential conflict of interest.

\section{Author's contributions}

MJ wrote the first draft of the manuscript. AW revised the manuscript. Both authors' read and approved the final manuscript.

\section{Author details}

${ }^{1}$ Third Department of Psychiatry, Institute of Psychiatry and Neurology, Sobieskiego 9, 02-957 Warsaw, Poland.

${ }^{2}$ Department of Clinical Neurophysiology, Institute of Psychiatry and Neurology, Sobieskiego 9, 02-957, Warsaw, Poland.

Received: 2 February 2015 Accepted: 1 June 2015

Published online: 16 September 2015

\section{References}

Alho K (1995) Cerebral generators of mismatch negativity (MMN) and its magnetic counterpart (MMNm) elicited by sound changes. Ear Hear 16:38-51

Baldeweg T, Hirsch SR (2014) Mismatch negativity indexes illness-specific impairments of cortical plasticity in schizophrenia: a comparison with bipolar disorder and Alzheimer's disease. Int J Psychophysiol. doi:10.1016/j.jpsycho.2014.03.008

Baldeweg T, Klugman A, Gruzelier JH, Hirsch SR (2002) Impairment in frontal but not temporal components of mismatch negativity in schizophrenia. Int J Psychophysiol 43:111-122

Baldeweg T, Klugman A, Gruzelier J, Hirsch SR (2004) Mismatch negativity potentials and cognitive impairment in schizophrenia. Schizophr Res 69:203-217

Bekinschtein TA, Dehaene S, Rohaut B, Tadel F, Cohen L, Naccache L (2009) Neural signature of the conscious processing of auditory regularities. Proc Natl Acad Sci U S A 106:1672-1677

Bodatsch M, Ruhrmann S, Wagner M, Mller R, Schultze-Lutter F, Frommann I et al (2011) Prediction of psychosis by mismatch negativity. Biol Psychiatry 69:959-966

Brenner CA, Krishnan GP, Vohs JL, Ahn W-Y, Hetrick WP, Morzorati SL et al (2009) Steady state responses: electrophysiological assessment of sensory function in schizophrenia. Schizophr Bull 35:1065-107

Butler PD, Martinez A, Foxe JJ, Kim D, Zemon V, Silipo G et al (2007) Subcortical visual dysfunction in schizophrenia drives secondary cortical impairments. Brain 130:417-430

Campanella S, Colin C (2014) Event-related potentials and biomarkers of psychiatric diseases: the necessity to adopt and develop multi-site guidelines. Front Behav Neurosci 8:428. doi:10.3389/fnbeh.2014.00428

Chang Y, Xu J, Shi N, Pang X, Zhang B, Cai Z (2011) Dysfunction of preattentive visual information processing among patients with major depressive disorder. Biol Psychiatry 69:742-747

Cheng CH, Baillet S, Hsiao FJ, Lin YY (2013a) Effects of aging on neuromagnetic mismatch responses to pitch changes. Neurosci Lett 544:20-24

Cheng CH, Hsu WY, Lin YY (2013b) Effects of physiological aging on mismatch negativity: a meta-analysis. Int J Psychophysiol 90:165-171

Csukly G, Stefanics G, Komlósi S, Czigler I, Czobor P (2013) Emotion-related visual mismatch responses in schizophrenia: impairments and correlations with emotion recognition. PLoS One 8(10), e75444. doi:10.1371/journal.pone.0075444

Duncan CC, Barry RJ, Connolly JF, Fischer C, Michie PT, Näätänen R et al (2009) Event-related potentials in clinical research: guidelines for eliciting, recording, and quantifying mismatch negativity, P300, and N400. Clin Neurophysiol 120:1883-1908 
Fan YT, Cheng Y (2014) Atypical mismatch negativity in response to emotional voices in people with autism spectrum conditions. PLoS One 9(7), e102471. doi:10.1371/journal.pone.0102471

Fisher DJ, Labelle A, Knott VJ (2008a) The right profile: mismatch negativity in schizophrenia with and without auditory hallucinations as measured by a multi-feature paradigm. Clin Neurophysiol 119:909-921

Fisher DJ, Labelle A, Knott VJ (2008b) Auditory hallucinations and the mismatch negativity: processing speech and nonspeech sounds in schizophrenia. Int J Psychophysiol 70:3-15

Fisher DJ, Grant B, Smith DM, Borracci G, Labelle A, Knott VJ (2011a) Effects of auditory hallucinations on the mismatch negativity (MMN) in schizophrenia as measured by a modified "optimal" multi-feature paradigm. Int J Psychophysiol $81: 245-251$

Fisher DJ, Grant B, Smith DM, Knott VJ (2011b) Effects of deviant probability on the "optimal" multi-feature mismatch negativity (MMN) paradigm. Int J Psychophysiol 79:311-315

Fisher DJ, Grant B, Smith DM, Borracci G, Labelle A, Knott VJ (2012a) Nicotine and the hallucinating brain: Effects on mismatch negativity (MMN) in schizophrenia. Psychiatry Res 196:181-187

Fisher DJ, Labelle A, Knott VJ (2012b) Alterations of mismatch negativity (MMN) in schizophrenia patients with auditory hallucinations experiencing acute exacerbation of illness. Schizophr Res 139:237-245

Fisher DJ, Smith DM, Labelle A, Knott VJ (2014) Attenuation of mismatch negativity (MMN) and novelty P300 in schizophrenia patients with auditory hallucinations experiencing acute exacerbation of illness. Biol Psychol 100:43-49

Friedman T, Sehatpour P, Dias E, Perrin M, Javitt DC (2012) Differential relationships of mismatch negativity and visual P1 deficits to premorbid characteristics and functional outcome in schizophrenia. Biol Psychiatry 71:521-529

Garrido MI, Kilner JM, Stephan KE, Friston KJ (2009) The mismatch negativity: a review of underlying mechanisms. Clin Neurophysiol 120:453-463

Gjini K, Arfken C, Boutros NN (2010) Relationships between sensory "gating out" and sensory "gating in" of auditory evoked potentials in schizophrenia: a pilot study. Schizophr Res 121:139-145

Green MF, Butler PD, Chen Y, Geyer M, Silverstein S, Wynn JK, Yoon JH, Zemon V (2009) Perception measurement in clinical trials of schizophrenia: promising paradigms from CNTRICS. Schizophr Bull 35:163-181

Hermens DF, Ward PB, Hodge MAR, Kaur M, Naismith SL, Hickie IB (2010) Impaired MMN/P3a complex in first-episode psychosis: cognitive and psychosocial associations. Prog Neuro-Psychopharmacology Biol Psychiatry 34:822-829

Higuchi Y, Seo T, Miyanishi T, Kawasaki Y, Suzuki M, Sumiyoshi T (2014) Mismatch negativity and p3a/reorienting complex in subjects with schizophrenia or at-risk mental state. Front Behav Neurosci 8:172. doi:10.3389/fnbeh. 2014.00172

Hooker C, Park S (2002) Emotion processing and its relationship to social functioning in schizophrenia patients. Psychiatry Res 112:41-50

Horton J, Millar A, Labelle A, Knott VJ (2011) MMN responsivity to manipulations of frequency and duration deviants in chronic, clozapine-treated schizophrenia patients. Schizophr Res 126:202-211

Jahshan C, Cadenhead KS, Rissling AJ, Kirihara K, Braff DL, Light GA (2012) Automatic sensory information processing abnormalities across the illness course of schizophrenia. Psychol Med 42:85-97

Jahshan C, Wynn JK, Green MF (2013) Relationship between auditory processing and affective prosody in schizophrenia. Schizophr Res 143:348-353

Javitt DC, Steinschneider M, Schroeder CE, Arezzo JC (1996) Role of cortical N-methyl-D-aspartate receptors in auditory sensory memory and mismatch negativity generation: implications for schizophrenia. Proc Natl Acad Sci U S A 93:11962-11967

Javitt DC, Grochowski S, Shelley AM, Ritter W (1998) Impaired mismatch negativity (MMN) generation in schizophrenia as a function of stimulus deviance, probability, and interstimulus/interdeviant interval. Electroencephalogr Clin Neurophysiol 108:143-153

Javitt DC, Zukin SR, Heresco-Levy U, Umbricht D (2012) Has an angel shown the way? Etiological and therapeutic implications of the PCP/NMDA model of schizophrenia. Schizophr Bull 38:958-966

Kasai K, Nakagome K, Hiramatsu Kl, Fukuda M, Honda M, Iwanami A (2002) Psychophysiological index during auditory selective attention correlates with visual continuous performance test sensitivity in normal adults. Int J Psychophysiol 45:211-225

Kawakubo Y, Kamio S, Nose T, Iwanami A, Nakagome K, Fukuda M, Kato N, Rogers MA, Kasai K (2007) Phonetic mismatch negativity predicts social skills acquisition in schizophrenia. Psychiatry Res 152:261-265

Kiang M, Braff DL, Sprock J, Light GA (2009) The relationship between preattentive sensory processing deficits and age in schizophrenia patients. Clin Neurophysiol 120:1949-1957

Kreegipuu K, Kuldkepp N, Sibolt O, Toom M, Allik J, Näätänen R (2013) vMMN for schematic faces: automatic detection of change in emotional expression. Front Hum Neurosci 7:714. doi:10.3389/fnhum.2013.00714

Kreitschmann-Andermahr I, Rosburg T, Meier T, Volz HP, Nowak H, Sauer H (1999) Impaired sensory processing in male patients with schizophrenia: A magnetoencephalographic study of auditory mismatch detection. Schizophr Res 35:121-129

Lavie N, Hirst A, Fockert JW, Viding E (2004) Load theory of selective attention and cognitive control. J Exp Psychol Gen 133:339-354

Lavie N, Beck DM, Konstantinou N (2014) Blinded by the load: attention, awareness and the role of perceptual load. Philos Trans R Soc L B Biol Sci 369:20130205. doi:10.1098/rstb.2013.0205

Light GA, Braff DL (2005a) Mismatch negativity deficits are associated with poor functioning in schizophrenia patients. Arch Gen Psychiatry 62:127-136

Light GA, Braff DL (2005b) Stability of mismatch negativity deficits and their relationship to functional impairments in chronic schizophrenia. Am J Psychiatry 162:1741-1743

Light GA, Näätänen R (2013) Mismatch negativity is a breakthrough biomarker for understanding and treating psychotic disorders. Proc Natl Acad Sci U S A 110:15175-6

Light GA, Swerdlow NR, Rissling AJ, Radant A, Sugar CA, Sprock J et al (2012) Characterization of neurophysiologic and neurocognitive biomarkers for use in genomic and clinical outcome studies of schizophrenia. PLoS One 7(7), e39434. doi:10.1371/journal.pone.0039434 
Luck SJ, Mathalon DH, O'Donnell BF, Hämäläinen MS, Spencer KM, Javitt DC et al (2011) A roadmap for the development and validation of event-related potential biomarkers in schizophrenia research. Biol Psychiatry 70:28-34

Macdonald M, Campbell K (2013) Event-related potential measures of a violation of an expected increase and decrease in intensity. PLoS One 8(10), e76897. doi:10.1371/journal.pone.0076897

Maekawa T, Katsuki S, Kishimoto J, Onitsuka T, Ogata K, Yamasaki T et al (2013) Altered visual information processing systems in bipolar disorder: evidence from visual MMN and P3. Front Hum Neurosci 7:403. doi:10.3389/fnhum. 2013.00403

Matthews N, Todd J, Budd TW, Cooper G, Michie PT (2007) Auditory lateralization in schizophrenia - mismatch negativity and behavioral evidence of a selective impairment in encoding interaural time cues. Clin Neurophysiol 118:833-844

Michie PT, Budd TW, Todd J, Rock D, Wichmann H, Box J et al (2000) Duration and frequency mismatch negativity in schizophrenia. Clin Neurophysiol 111:1054-1065

Näätänen R, Kähkönen S (2009) Central auditory dysfunction in schizophrenia as revealed by the mismatch negativity (MMN) and its magnetic equivalent MMNm: a review. Int J Neuropsychopharmacol 12:125-135

Näätänen R, Gaillard AW, Mäntysalo S (1978) Early selective-attention effect on evoked potential reinterpreted. Acta Psychol (Amst) 42:313-329

Näätänen R, Pakarinen S, Rinne T, Takegata R (2004) The mismatch negativity (MMN): towards the optimal paradigm. Clin Neurophysiol 115:140-144

Näätänen R, Kujala T, Kreegipuu K, Carlson S, Escera C, Baldeweg T et al (2011) The mismatch negativity: an index of cognitive decline in neuropsychiatric and neurological diseases and in ageing. Brain 134:3432-3450

Näätänen R, Kujala T, Escera C, Baldeweg T, Kreegipuu K, Carlson S et al (2012) The mismatch negativity (MMN) - a unique window to disturbed central auditory processing in ageing and different clinical conditions. Clin Neurophysiol 123:424-458

Näätänen R, Sussman ES, Salisbury D, Shafer VL (2014) Mismatch negativity (MMN) as an index of cognitive dysfunction. Brain Topogr 27:451-466

Näätänen R, Shiga T, Asano S, Yabe H (2015) Mismatch negativity (MMN) deficiency : a break-through biomarker in predicting psychosis onset. Int J Psychophysiol. doi:10.1016/j.jpsycho.2014.12.012

Nagai T, Tada M, Kirihara K, Araki T, Jinde S, Kasai K (2013a) Mismatch negativity as a "translatable" brain marker toward early intervention for psychosis: a review. Front psychiatry 4:115. doi:10.3389/fpsyt.2013.00115

Nagai T, Tada M, Kirihara K, Yahata N, Hashimoto R, Araki T et al (2013b) Auditory mismatch negativity and P3a in response to duration and frequency changes in the early stages of psychosis. Schizophr Res 150:547-554

Neuhaus AH, Brandt ESL, Goldberg TE, Bates J, Malhotra AK (2013) Evidence for impaired visual prediction error in schizophrenia. Schizophr Res 147:326-330

Pakarinen S, Huotilainen M, Näätänen R (2010) The mismatch negativity (MMN) with no standard stimulus. Clin Neurophysiol 121:1043-1050

Perez VB, Woods SW, Roach BJ, Ford JM, McGlashan TH, Srihari VH et al (2014) Automatic auditory processing deficits in schizophrenia and clinical high-risk patients: forecasting psychosis risk with mismatch negativity. Biol Psychiatry 75:459-469

Rasser PE, Schall U, Todd J, Michie PT, Ward PB, Johnston P et al (2011) Gray matter deficits, mismatch negativity, and outcomes in schizophrenia. Schizophr Bull 37:131-140

Rissling AJ, Braff DL, Swerdlow NR, Hellemann G, Rassovsky Y, Sprock J et al (2012) Disentangling early sensory information processing deficits in schizophrenia. Clin Neurophysiol 123:1942-9

Rissling AJ, Park SH, Young JW, Rissling MB, Sugar C, Sprock J, Mathias DJ, Pela M, Sharp RF, Braff DL, Light GA (2013) Demand and modality of directed attention modulate "pre-attentive" sensory processes in schizophrenia patients and nonpsychiatric controls. Schizophr Res 146:326-335

Salisbury DF, Shenton ME, Griggs CB, Bonner-Jackson A, McCarley RW (2002) Mismatch negativity in chronic schizophrenia and first-episode schizophrenia. Arch Gen Psychiatry 59:686-694

Schmidt A, Bachmann R, Kometer M, Csomor PA, Stephan KE, Seifritz E et al (2012) Mismatch negativity encoding of prediction errors predicts S-ketamine-induced cognitive impairments. Neuropsychopharmacology 37:865-875

Schmidt A, Diaconescu AO, Kometer M, Friston KJ, Stephan KE, Vollenweider FX (2013) Modeling ketamine effects on synaptic plasticity during the mismatch negativity. Cereb Cortex 23:2394-2406

Shelley AM, Ward PB, Catts SV, Michie PT, Andrews S, McConaghy N (1991) Mismatch negativity: an index of a preattentive processing deficit in schizophrenia. Biol Psychiatry 30:1059-1062

Shin KS, Kim JS, Kim SN, Koh Y, Jang JH, An SK et al (2012) Aberrant auditory processing in schizophrenia and in subjects at ultra-high-risk for psychosis. Schizophr Bull 38:1258-1267

Stefanics G, Kremlacek J, Czigler I (2014) Visual mismatch negativity: a predictive coding view. Front Hum Neurosci 8:1-19

Susac A, Ilmoniemi RJ, Pihko E, Supek S (2004) Neurodynamic studies on emotional and inverted faces in an oddball paradigm. Brain Topogr 16:265-268

Thönnessen H, Zvyagintsev M, Harke KC, Boers F, Dammers J, Norra C et al (2008) Optimized mismatch negativity paradigm reflects deficits in schizophrenia patients. a combined EEG and MEG study. Biol Psychol 77:205-216

Tiitinen H, Alho K, Huotilainen M, Ilmoniemi RJ, Simola J, Näätänen R (1993) Tonotopic auditory cortex and the magnetoencephalographic (MEG) equivalent of the mismatch negativity. Psychophysiology 30:537-540

Todd J, Michie PT, Schall U, Karayanidis F, Yabe H, Näätänen R (2008) Deviant matters: duration, frequency, and intensity deviants reveal different patterns of mismatch negativity reduction in early and late schizophrenia. Biol Psychiatry 63:58-64

Todd J, Harms L, Schall U, Michie PT (2013) Mismatch negativity: translating the potential. Front Psychiatry 4:1-22. doi:10.3389/fpsyt.2013.00171

Todd J, Whitson L, Smith E, Michie PT, Schall U, Ward PB (2014) What's intact and what's not within the mismatch negativity system in schizophrenia. Psychophysiology 51:337-47

Umbricht D, Krljes S (2005) Mismatch negativity in schizophrenia: a meta-analysis. Schizophr Res 76:1-23

Umbricht D, Schmid L, Koller R, Vollenweider FX, Hell D, Javitt DC (2000) Ketamine-induced deficits in auditory and visual context-dependent processing in healthy volunteers: implications for models of cognitive deficits in schizophrenia. Arch Gen Psychiatry 57:1139-1147 
Umbricht D, Koller R, Vollenweider FX, Schmid L (2002) Mismatch negativity predicts psychotic experiences induced by NMDA receptor antagonist in healthy volunteers. Biol Psychiatry 51:400-406

Umbricht D, Koller R, Schmid L, Skrabo A, Grübel C, Huber T et al (2003) How specific are deficits in mismatch negativity generation to schizophrenia? Biol Psychiatry 53:1120-1131

Urban A, Kremláček J, Masopust J, Libiger J (2008) Visual mismatch negativity among patients with schizophrenia. Schizophr Res 102:320-328

Wacongne C, Labyt E, van Wassenhove V, Bekinschtein T, Naccache L, Dehaene S (2011) Evidence for a hierarchy of predictions and prediction errors in human cortex. Proc Natl Acad Sci 108:20754-20759

Wang X (2013) The harmonic organization of auditory cortex. Front Syst Neurosci 7:114. doi:10.3389/fnsys.2013.00114

Winkler I (2007) Interpreting the mismatch negativity. J Psychophysiol 21:147-163

Wynn JK, Sugar C, Horan WP, Kern R, Green MF (2010) Mismatch negativity, social cognition, and functioning in schizophrenia patients. Biol Psychiatry 67:940-947

Zion-Golumbic E, Deouell LY, Whalen DH, Bentin S (2007) Representation of harmonic frequencies in auditory memory: a mismatch negativity study. Psychophysiology 44:671-67

\section{Submit your next manuscript to BioMed Central and take full advantage of:}

- Convenient online submission

- Thorough peer review

- No space constraints or color figure charges

- Immediate publication on acceptance

- Inclusion in PubMed, CAS, Scopus and Google Scholar

- Research which is freely available for redistribution 